\title{
Instrumentos de planejamento e preparo dos municípios brasileiros à Política de Proteção e Defesa Civil
}

\author{
Brazilian municipalities planning and prepare tools for Protection Policy and \\ Civil Defense
}

Marcos Pellegrini Coutinho $0^{[0]}$, Luciana de Resende Londe ${ }^{[a]}$, Leonardo Bacelar Lima Santos ${ }^{[0]}$, Paulo Jorge Vaitsman Lea ${ }^{[b]}$

\section{Resumo}

Com a premissa de que as cidades devem possuir um plano diretor e leis capazes de inibir ocupação em áreas de risco, buscamos conhecer o nível de preparo dos municípios brasileiros no contexto da Política Nacional de Proteção e Defesa Civil (PNPDEC), segundo a Lei n. 12.608/2012, que altera o Estatuto da Cidade e a Lei de Lehmann. A pesquisa utilizou os dados do MUNIC/IBGE/2013, que disponibiliza informações dos municípios. Constatamos que poucos municípios incorporaram as mudanças trazidas pela PNPDEC, inclusive municípios com áreas de risco mapeadas e monitoradas pelos órgãos competentes. Sugerimos uma dedicação especial dos setores de planejamento, obras e infraestrutura, defesa civil, ambiental, saúde, entre outros, para que os instrumentos normativos sejam utilizados no planejamento das cidades, conforme critérios técnicos e fragilidades ambientais. A capacitação técnica e da população também é essencial para uma ocupação ordenada dos espaços (público e privado) e para a construção de cidades resilientes.

Palavras-chave: Ordenamento na ocupação do espaço urbano. Política nacional de proteção e defesa civil. Áreas de risco.

\section{Abstract}

Assuming that municipalities must follow a master plan and laws capable to stop risk areas occupation, we sought to understand the Brazilian municipalities' preparedness level in the context of National Protection Policy of Protection and Civil Defense - PNPDEC - (Law 12.608/2012), which changes Brazilian Lehmann's Law and Brazilian Cities' Statute. This research used data from the dataset from the Municipalities Basic Information Research Query - MUNIC/IBGE/2013. We concluded that few municipalities incorporated the PNPDEC directions. Some of them, although having mapped and monitored risk areas, have not adapted to those new directions, including municipalities with risk areas mapped and monitored by the relevant bodies. We suggest special attention from the sectors of planning, construction and infrastructure, civil defense,

MPC é mestre em Produção Vegetal, e-mail: mzpcoutinho@yahoo.com.br LRL é doutora em Sensoriamento Remoto, e-mail: luciana.londe@cemaden.gov.br LBLS é doutor em Computação Aplicada, e-mail: leonardo.santos@cemaden.gov.br PJVL é doutor em Geografia, e-mail: pjvleal@hotmail.com 
environmental, health, etc. so that normative instruments are used in the city's planning, as technical criteria and environmental weaknesses. Technical and popular training is also essential for a organized occupation (public and private) and to build resilient cities.

Keywords: Urban land use planning. National protection policy and civil defense. Risk areas.

\section{Introdução}

A Constituição Federal de 1988, em seu art. 30, VII, atribuiu aos municípios competência para: "Promover, no que couber, adequado ordenamento territorial, mediante planejamento e controle do uso, do parcelamento e da ocupação do solo urbano" (Brasil, 1988).

Dessa forma, é importante que os municípios busquem a ocupação e o uso do solo, considerando as fragilidades e as potencialidades de seus territórios.

Robaina et al. (2010, p. 159) afirmam que

[a] expansão urbana ocorrida nas últimas décadas, associada com a incapacidade do Estado em atender a demanda de moradias, levou a população, principalmente a de baixa renda, a ocupar áreas sujeitas a processos de dinâmica superficial desencadeadores de risco, como planícies de inundação e encostas de morros.

A urbanização desordenada agrava o quadro de exclusão social, aumenta a violência e tem impactado o ambiente, trazendo como consequências as enchentes, os deslizamentos, as erosões e outras situações que geram prejuízos humanos e materiais e que colocam em risco vidas humanas (Ribeiro et al., 2011). Diferente de países que enfrentam fenômenos de origem totalmente natural, como terremotos, vulcões e furacões, o Brasil apresenta ocorrências associadas à ação humana, especialmente referentes às relações entre a expansão urbana e as características naturais dos terrenos ocupados (Santos, 2012).

Os riscos socioambientais podem ser reduzidos e evitados por meio de uma gestão eficiente da terra e dos recursos ambientais (UNISDR, 2009). Portanto, é importante planejar e executar medidas para prevenção ou minimização de desastres em articulação com outros temas e setores, segmentos governamentais ou não governamentais e sociedade. A negligência, por parte da gestão municipal, com relação às áreas de risco e à população vulnerável, traz prejuízos que extrapolam o âmbito local.
No Brasil, em 2012, foi instituída a Política Nacional de Proteção e Defesa Civil (PNPDEC) (Lei n. 12.608), que estabelece as atribuições governamentais nas esferas federal, estadual e municipal para enfrentar esses eventos e minimizar riscos e impactos de desastres, considerando aspectos legais e administrativos.

A PNPDEC, em seu art. 8o, estabeleceu para os municípios as seguintes competências, entre outras:

III - incorporar as ações de proteção e defesa civil no planejamento municipal;

IV - identificar e mapear as áreas de risco de desastres;

$\mathrm{V}$ - promover a fiscalização das áreas de risco de desastre e vedar novas ocupações nessas áreas;

IX - manter a população informada sobre áreas de risco e ocorrência de eventos extremos, bem como sobre protocolos de prevenção e alerta e sobre as ações emergenciais em circunstâncias de desastres (Brasil, 2012).

Na esfera federal, foi criado o Centro Nacional de Monitoramento e Alertas de Desastres Naturais (CEMADEN), responsável pela emissão de alertas de desastres ao Centro Nacional de Gerenciamento de Riscos e Desastres (CENAD), o qual, por sua vez, faz a comunicação com os órgãos municipais de defesa civil. Para que essa cadeia de ações seja efetiva, é necessário que os municípios estejam devidamente preparados e com planejamentos adequados aos seus respectivos cenários de risco.

Observa-se que as cidades devem se preparar para um maior número de dias quentes e de dias mais frios, maiores dificuldades para dispersão de poluentes, maior número de ocorrências de chuvas intensas, com inundações e enchentes, prevendo-se aumento do valor dos seguros, desvalorização de imóveis, aumento da demanda de reformas, de demolições, novas construções e adaptações de todas as infraestruturas de circulação, saneamento, comunicações e energia (Bueno, 2011). De acordo com Boff (2010) e Maffra \& 
Mazzola (2007), os ecossistemas com a interferência antrópica tornaram-se cada vez mais vulneráveis, principalmente devido aos processos de deterioração e de degradação ambiental.

Considerando que a redução dos desastres socioambientais em áreas urbanas requer estratégias e ações realizadas antecipadamente, analisamos alguns instrumentos de planejamento dos municípios brasileiros, como o plano diretor e outros instrumentos capazes de promover a ocupação planejada do território, a partir de dados do Instituto Brasileiro de Geografia e Estatística (IBGE, 2014), no contexto da PNPDEC (Brasil, 2012).

\section{Fundamentação teórica}

Marandola \& Hogan (2004) apontam que pobreza e desigualdade, de um lado, e ambiente, de outro, formam os dois principais temas nos atuais estudos da vulnerabilidade.

Analisando diferentes abordagens sobre vulnerabilidade, Cutter (1996) aponta que a diversidade dos temas e as suas práticas metodológicas podem ser agrupadas em três posturas principais: 1 . Destaque para a exposição (biofísica ou tecnológica); 2. Destaque para consequências adversas (vulnerabilidade social); 3. A combinação das duas anteriores.

Alves \& Torres (2006), em consonância com Cutter (1996) e considerando as diferenças entre vulnerabilidade social (analisada em relação a indivíduos, famílias ou grupos sociais) e vulnerabilidade ambiental (analisada em relação a regiões e ecossistemas), usam o termo vulnerabilidade socioambiental na integração das dimensões social e ambiental.

Entre as principais causas dos desastres socioambientais, Ferreira et al. (2011) destacam a ocupação incorreta do solo, a ineficácia política nos âmbitos municipal, estadual e/ou federal, a fraca organização dos serviços de defesa civil e a dificuldade de envolvimento das comunidades em atividades de prevenção.

Os escorregamentos e as inundações, no Brasil, estão associados, principalmente, à utilização do solo para atividades antrópicas, sem o cuidado de harmonizar o desenvolvimento econômico e social e as questões ambientais (Robaina, 2008).

Santos (2012) argumenta que, no Brasil, os desastres estão fortemente associados à ação humana, especialmente com relação ao modo de atuação das administrações públicas e privadas para lidar com as relações entre a expansão urbana e as características naturais dos terrenos ocupados. Netto \& Avelar (2007) dão destaque para as áreas de favelas, tanto em encostas como em planícies costeiras, as quais tornam-se especialmente vulneráveis aos perigos relacionados a chuvas intensas.

0 crescimento urbano não controlado nos setores em risco pode ser compreendido pelo baixo valor venal e/ou disponibilidade dos terrenos nesses locais, seguido de um posterior processo de urbanização, porém a ocupação deveria ser inibida pelos instrumentos do Estatuto da Cidade (Collischonn, 2009). Quando ocorre a ocupação sem o devido planejamento do espaço de risco, os impactos são significativos (Tucci, 2005).

No planejamento e no controle do uso do espaço, do parcelamento e da ocupação do solo urbano, os municípios têm competência para promover um ordenamento territorial adequado quando for necessário e legislar sobre assuntos de interesse local (Martins, 2003).

A inibição da ocupação de áreas ambientalmente vulneráveis e de risco e a promoção da realocação da população residente nessas áreas estão entre os objetivos da Lei Federal n. 12.608/12, que institui a PNPDEC, reforçando, assim, a necessária atuação dos estados e municípios nas suas respectivas competências suplementares (Coutinho et al., 2013).

0 Estatuto da Cidade e a Lei n. 6.766/79 foram alterados pela Lei n. 12.608/2012 (Brasil, 2012), passando a exigir que os municípios que pretendam ampliar o perímetro urbano apresentem projeto específico que contenha informações de ameaça de desastres naturais (Ganem, 2012). De acordo com a autora, a partir de abril de 2014, a aprovação do projeto de parcelamento ficou vinculada ao atendimento dos requisitos constantes da carta geotécnica de aptidão à urbanização, nos municípios inseridos no cadastro nacional de municípios com áreas suscetíveis à ocorrência de deslizamentos de grande impacto, inundações bruscas ou processos geológicos ou hidrológicos correlatos.

O plano diretor é o instrumento básico da política municipal de desenvolvimento e expansão urbana, tendo como objetivo ordenar o desenvolvimento das funções sociais da cidade e garantir o bem-estar de seus habitantes (Carvalho \& Braga, 2001). A maneira como o espaço é utilizado nas cidades pode ter impactos severos, sendo necessário orientar a expansão urbana, investir em infraestrutura básica, promover 
a conservação de espaços abertos e a proteção de recursos naturais e também a equidade no uso do espaço público (Martine, 2007).

0 plano diretor deve incluir, entre outras informações, o levantamento das áreas de risco com base em carta geotécnica, medidas de drenagem urbana e diretrizes para a regularização fundiária de assentamentos urbanos irregulares (Ganem, 2012).

Nos municípios com expectativa de crescimento, é importante que seja feito o mapeamento de áreas susceptíveis a fenômenos naturais para que o crescimento não ocorra sobre as áreas de risco (Goerl, 2010). Também é possível realizar um zoneamento do território para promover usos produtivos e menos sujeitos a danos, permitindo a manutenção de áreas de uso social, como áreas verdes urbanas e áreas de uso recreacional (Menezes, 2014).

As ações de gerenciamento de áreas de risco e de prevenção de acidentes (deslizamentos e inundações), se baseadas em preceitos legais, tornam mais eficazes os trabalhos da defesa civil (Brasil, 2007).

Os danos e os prejuízos decorrentes de deslizamentos podem ser diminuídos ao impedir o aparecimento ou o crescimento de áreas e de situações de risco. Para tanto, é essencial planejar o uso e a ocupação do território, considerando as características e as limitações naturais do terreno (Vedovello \& Macedo, 2007), além de adoções de medidas complementares em apoio às intervenções planejadas.

\section{Método}

A análise do preparo dos municípios para enfrentamento dos desastres foi realizada a partir de dados da $11^{a}$ edição do Questionário Básico da Pesquisa de Informações Básicas Municipais (IBGE, 2014), disponíveis na página do IBGE (IBGE, 2014). É importante mencionar que o MUNIC 2013 investigou os 5.570 municípios do Brasil.

Neste trabalho, usamos como fonte específica de pesquisa os dados referentes à legislação e aos instrumentos de ordenamento e de planejamento, como leis sobre o uso e ocupação do solo, plano diretor, carta geotécnica e mapeamento de áreas de risco, disponíveis na base de dados do MUNIC. Além disso, foi feita uma análise para os municípios com risco geológico e hídrico (alagamentos, enxurradas e inundações) monitorados pelo CEMADEN. Os principais instrumentos analisados, que servem de base para os municípios e aplicações, estão organizados na Tabela 1.

A elaboração de mapas foi realizada por meio do Sistema de Informações Geográficas TerraView (TerraView, 2014). Nesta análise, considerou-se a existência dos instrumentos mencionados na Tabela 1.

As informações foram organizadas considerando as mudanças trazidas pela PNPDEC em outras normas relacionadas à ocupação dos territórios e a sua relação com as áreas de risco, a exemplo do Estatuto da Cidade e da Lei de Lehmann.

\section{Resultados e discussão}

\section{Plano diretor}

O plano diretor é obrigatório para cidades: "Incluídas no cadastro nacional de Municípios com áreas suscetíveis à ocorrência de deslizamentos de grande impacto, inundações bruscas ou processos geológicos ou hidrológicos correlatos" (Brasil, 2001, art. 41, VI).

O Estatuto das Cidades indica o caminho para reverter o processo inadequado de ocupação do espaço urbano ao incorporar diretrizes para o uso e ocupação do solo, para a preservação e ocupação de áreas verdes, de forma a reduzir a impermeabilização das cidades, bem como ações de intervenção preventiva e de realocação de população das áreas de risco, regularização fundiária e medidas estruturais, conforme art. 42 A, incisos I, II, III, IV, V e VI, a seguir apresentados:

I - parâmetros de parcelamento, uso e ocupação do solo, de modo a promover a diversidade de usos e a contribuir para a geração de emprego e renda;

II - mapeamento contendo as áreas suscetíveis à ocorrência de deslizamentos de grande impacto, inundações bruscas ou processos geológicos ou hidrológicos correlatos;

III - planejamento de ações de intervenção preventiva e realocação de população de áreas de risco de desastre;

IV - medidas de drenagem urbana necessárias à prevenção e à mitigação de impactos de desastres; 
Tabela 1 - Instrumentos usados como fonte de pesquisa e sua importância

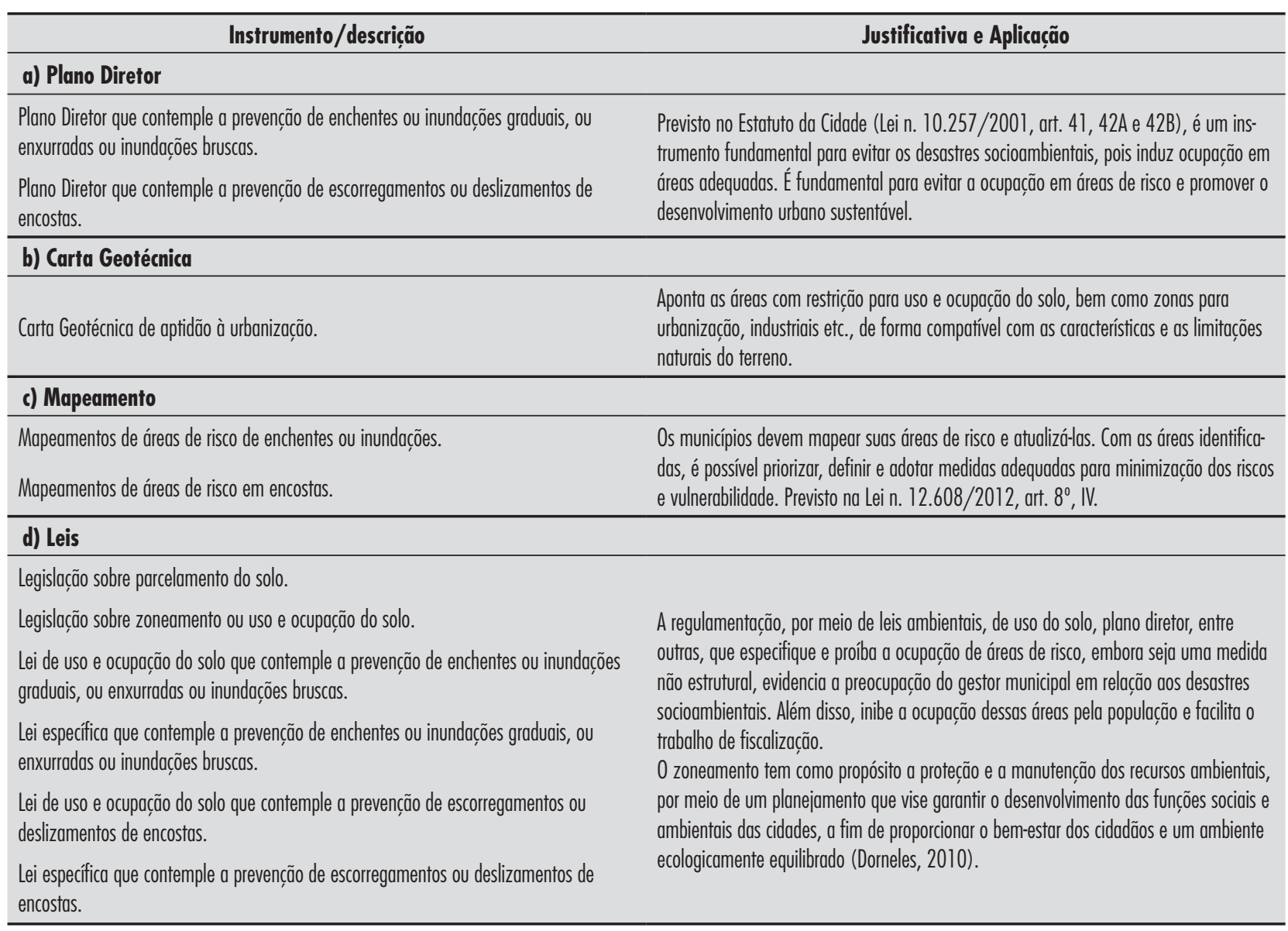

Fonte: adaptado do IBGE (2014).

V - diretrizes para a regularização fundiária de assentamentos urbanos irregulares, se houver, observadas a Lei $n^{\circ} 11.977$, de 7 de julho de 2009, e demais normas federais e estaduais pertinentes, e previsão de áreas para habitação de interesse social por meio da demarcação de zonas especiais de interesse social e de outros instrumentos de política urbana, onde o uso habitacional for permitido; e

VI - identificação e diretrizes para a preservação e ocupação das áreas verdes municipais, quando for o caso, com vistas à redução da impermeabilização das cidades (Brasil, 2001).

Cabe observar que uma relação adequada entre área verde e população é importante, pois as áreas verdes minimizam os efeitos da impermeabilização e regulam o microclima, amenizando as altas temperaturas produzidas pela concentração de áreas edificadas ou pavimentadas (Oliveira et al., 2013). Nesse contexto, torna-se importante ampliar áreas verdes nas cidades, de maneira a amenizar o clima local e o possível aumento da temperatura causado pelo aquecimento global, criando-se áreas verdes urbanas previstas no novo Código Florestal. Os municípios podem também criar leis (Santos, 2012) para estimular a criação de áreas permeáveis, favoráveis à infiltração de água no solo, ou para estimular o armazenamento de água em caixas d'água ou similares nos imóveis, de maneira a reter parte da água das chuvas. 0 proprietário do imóvel, ao cumprir a lei, seria beneficiado pagando IPTU diferenciado, pois estaria ajudando a reduzir os problemas urbanos, como os alagamentos e as inundações.

O plano diretor da cidade de São Paulo (SP) (Lei n. 16.050/2014) apresenta diretrizes importantes em relação aos sistemas de drenagens, que servem para evitar e para minimizar as inundações, ao prever, 
entre outras: "I - adequar as regras de uso e ocupação do solo ao regime fluvial nas várzeas; II - preservar e recuperar as áreas com interesse para drenagem, principalmente várzeas, faixas sanitárias, fundos de vale e cabeceiras de drenagem" (São Paulo, 2014).

Nota-se que as várzeas não podem ser intensamente ocupadas, pois são áreas de armazenamento e infiltração da água de diversos pontos da bacia hidrográfica e do extravasamento de cursos d'água, sendo necessário respeitar essa importante característica natural. Para Tucci (2005), em qualquer planejamento urbano, deve-se procurar manter a zona de passagem de enchentes desobstruída. Além disso, a preservação e a recuperação dessas áreas de várzeas, fundos de vales e cabeceiras de drenagem podem amenizar o número crescente de alagamentos e de inundações nas cidades, mostrando ser uma alternativa mais rentável do que construir estrutura física para a defesa contra enchentes ou instalações caras para tratamento de água (Medeiros, 2013).

De acordo com Santos (2012) e Tucci (2008), é preciso evitar o crescimento desordenado das cidades, o que modifica o ambiente e o sistema de drenagem e acarreta as enchentes urbanas.

A adoção de medidas que impeçam o crescimento periférico das cidades, principalmente em terrenos localizados nas margens de cursos d'água e nas encostas de morros, é importante para evitar o aumento da vulnerabilidade socioambiental dessas áreas e a contaminação da água, bem como para reduzir o aumento das jornadas entre o centro e as áreas periféricas e periurbanas, com consequente aumento do trânsito e da poluição do ar (Alves et al., 2008).

A PNPDEC também veda a concessão de licença ou alvará de construção em áreas de risco indicadas como não edificáveis no plano diretor ou na legislação dele derivada (Brasil, 2012, art. 23).

Um plano diretor com delimitação das áreas de risco e com medidas voltadas à minimização dos desastres socioambientais deve fazer parte da gestão municipal, sendo integrado ainda com outros instrumentos de planejamento, como o Plano Municipal de Redução de Risco (PMRR), o cadastro e o mapeamento das áreas de risco, a carta geotécnica e lei de uso e de ocupação do solo, entre outras. Cabe observar que o conteúdo do plano diretor deve ser compatível com as disposições contidas nos planos de recursos hídricos, formulados em conformidade com as Leis n. $9.433 / 1997$ e n. 10.257 , art. 42-A, § 2.
As respostas relacionadas a esse instrumento revelam que $64 \%$ dos municípios possuem o plano, incluindo os $14 \%$ que estavam em fase de elaboração, e apontam para a necessidade de criação desses planos, principalmente nas regiões Norte e Nordeste do país. Considerando-se que são regiões com potencial de crescimento e de expansão da urbanização, seria pertinente fomentar a criação de tais planos para que o prosseguimento dos processos de ocupação ocorra de forma legal, orientada e monitorada.

É importante mencionar que o plano diretor não é obrigatório para municípios com menos de $20 \mathrm{mil}$ habitantes. Entretanto, esses municípios também estão sujeitos aos impactos de desastres naturais. Assim, pelo menos aqueles constantes no cadastro de risco deveriam receber suporte para a criação de seus planos diretores. Além disso, a PNPDEC passou a exigir o plano para os municípios com áreas de risco, como instrumento básico da política de desenvolvimento e de expansão das cidades.

\section{Parcelamento do uso do solo e carta geotécnica}

A Lei de Parcelamento do Uso do Solo (Lei n. 6.766/67, ou de Lehmann, art. $3^{\circ}$ ) estabelece que: "Somente será admitido o parcelamento do solo para fins urbanos em zonas urbanas, de expansão urbana ou de urbanização específica, assim definidas pelo plano diretor ou aprovadas por lei municipal" (Brasil, 1979).

Assim, não é permitido o parcelamento do solo:

I - em terrenos alagadiços e sujeitos a inundações, antes de tomadas as providências para assegurar o escoamento das águas;

II - em terrenos que tenham sido aterrados com material nocivo à saúde pública, sem que sejam previamente saneados;

III - em terrenos com declividade igual ou superior a $30 \%$ (trinta por cento), salvo se atendidas exigências específicas das autoridades competentes;

IV - em terrenos onde as condições geológicas não aconselham a edificação;

V - em áreas de preservação ecológica ou naquelas onde a poluição impeça condições sanitárias suportáveis, até a sua correção (Brasil, 1979). 


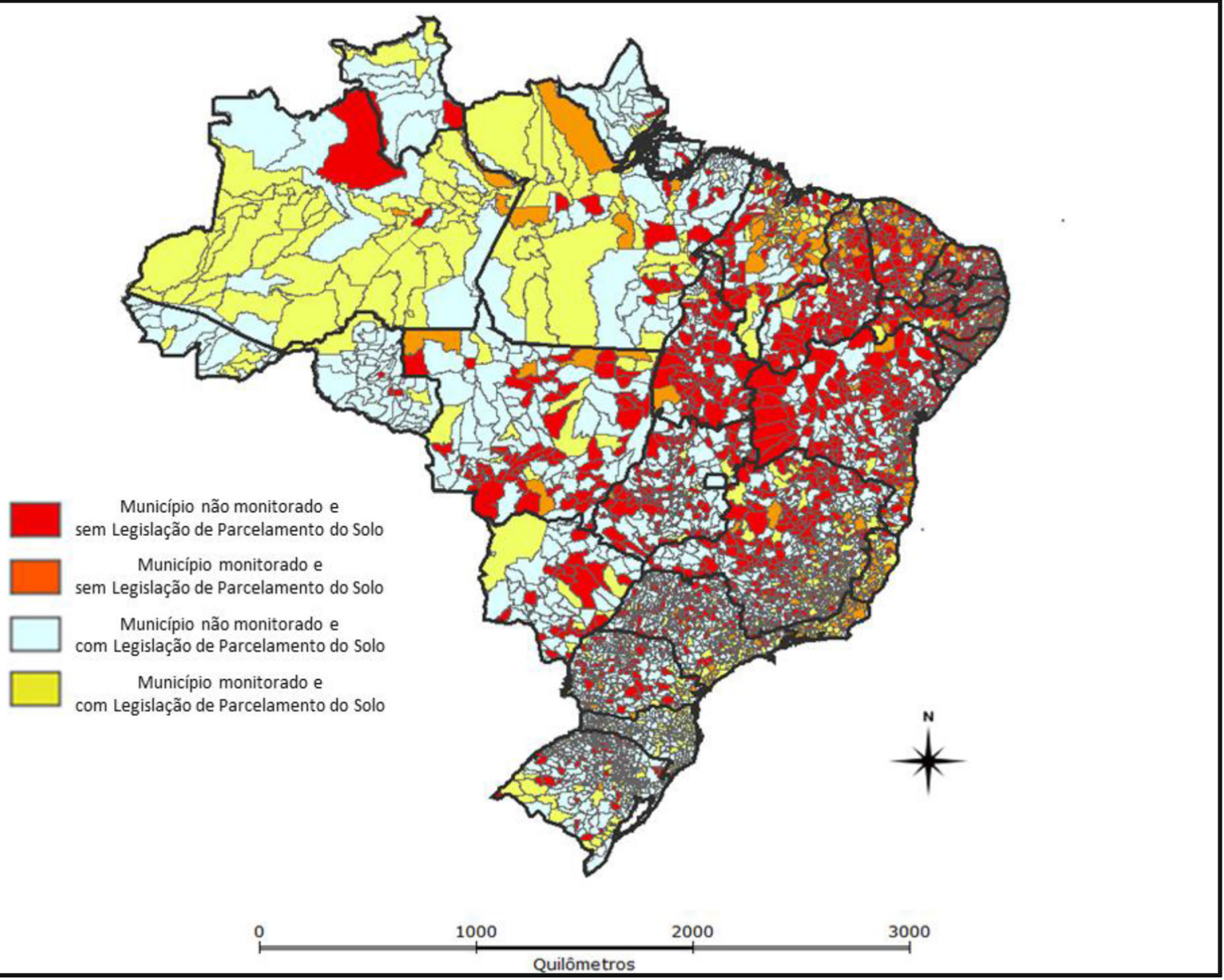

Figura 1 - Condição dos municípios brasileiros quanto à legislação municipal de parcelamento do solo e ao sistema de monitoramento do CEMADEN Fonte: IBGE (2014).

Pouco mais da metade dos municípios analisados (56\%) contempla leis sobre o parcelamento do solo. Alguns deles são monitorados pelo CEMADEN (cor laranja, Figura 1), porém o monitoramento por si só não atua nas causas do problema, tornando crucial a adoção dessas leis. Apesar de a PNPDEC prever que os municípios não devem permitir a ocupação de áreas de risco, os estados do Maranhão, Ceará, Espírito Santo e Rio de Janeiro são os mais carentes no estabelecimento de leis nessa temática. No entanto, verificamos que os estados do Amapá, Amazonas, Rio Grande do Sul e Santa Catarina merecem destaque, com municípios que são monitorados pelo CEMADEN e que possuem a referida legislação. A cidade de Blumenau (SC), por exemplo, possui um Código de Parcelamento do Solo, que estabelece a seguinte diretriz "[...] o parcelamento deverá ser projetado objetivando o desenvolvimento urbano integrado, de modo a se obter conjuntos urbanos incorporados ao sistema de circulação e aos logradouros, em função da sua localização, destino e uso, harmonizando-se com a topografia local" (Blumenau, 2010).

Santoro et al. (2009), analisando a expansão urbana sobre os mananciais de São Paulo, verificaram haver necessidade de política fundiária e de uso do solo não apenas restritiva, mas que verifique o histórico das propriedades não ocupadas e as suas potencialidades ambientais, de forma a propor usos compatíveis com a conservação de água. Os referidos autores observaram ainda que, apesar de existirem projetos nesse sentido, de iniciativa privada ou pública, não há a articulação em torno de uma política de proteção que oriente a ação pública e vá além da tentativa de aplicação da legislação de restrição de uso da propriedade, muitas vezes superada pelos próprios interesses privados. 
É possível expandir esse raciocínio para a maioria dos municípios do Brasil, nos quais a urbanização avança sobre os mananciais, bem como para áreas suscetíveis à inundação e ao deslizamento, pressionando o parcelamento e o uso do solo para fins urbanos, que são altamente lucrativos para uma minoria, mas acabam trazendo transtorno à população e ao poder público, em decorrência das áreas de risco também criadas.

Além disso, foi incorporado, por meio da PNPDEC, na Lei de Lehmann, para os municípios com riscos hidrológicos ou geológicos, conforme Capítulo V, que trata da aprovação de projeto de loteamento e de desmembramento, que estes deverão seguir os requisitos da carta geotécnica de aptidão à urbanização e não deverão autorizar o loteamento e o desmembramento em áreas de risco, conforme segue:

Nos Municípios inseridos no cadastro nacional de municípios com áreas suscetíveis à ocorrência de deslizamentos de grande impacto, inundações bruscas ou processos geológicos ou hidrológicos correlatos, a aprovação do projeto de que trata o caput ficará vinculada ao atendimento dos requisitos constantes da carta geotécnica de aptidão à urbanização (Brasil, 2012, art. 12, § 2).

É vedada a aprovação de projeto de loteamento e desmembramento em áreas de risco definidas como não edificáveis, no plano diretor ou em legislação dele derivada (Brasil, 2012, art. $12, \S 3)$.

Atualmente, com o apoio do Ministério das Cidades, as cartas geotécnicas de 106 municípios estão em fase de elaboração. Outros municípios com histórico de desastres socioambientais ou obras de engenharia de grande porte, como Santos (SP), São Vicente (SP), Guarujá (SP), Recife (PE), Campo Grande (MS) e Blumenau (SC), também possuem esta Carta.

Cabe ressaltar que as cartas geotécnicas constituem-se como uma das bases para a elaboração dos planos diretores dos municípios (Brasil, 2007) e uma das principais fontes de informação acerca da aptidão dos terrenos de um determinado município, assim como sobre a susceptibilidade aos processos que possam trazer riscos à população. A PNPDEC incluiu no Estatuto das Cidades (Lei n. 10.257/2001, art. 42-A, Inciso VI, § 1) o seguinte texto: "A identificação e o mapeamento de áreas de risco levarão em conta as cartas geotécnicas" (Brasil, 2001). Nota-se, portanto, que as cartas geotécnicas servem como norteadoras de outros instrumentos importantes e, ao serem elaboradas, podem gerar alterações nos mapeamentos de risco e nos planos diretores preexistentes, configurando um importante instrumento de gestão municipal.

\section{Mapeamento de áreas de risco}

A condição básica para um município ser monitorado pelo CEMADEN é possuir um mapeamento das áreas de risco de deslizamentos em encostas, de alagamentos e de enxurradas, de solapamentos e de terras caídas, além da estimativa da extensão dos prováveis danos decorrentes de um desastre (CEMADEN, 2014).

Alheiros (2006) observa que o mapeamento de risco é a base para o desenvolvimento do PMRR. Todavia, os resultados mostram que apenas 19\% dos municípios afirmam possuir mapeamentos de áreas de risco de enchentes ou inundações e 13\% dos municípios afirmam possuir mapeamentos de áreas de risco em encostas.

Alguns municípios não apresentam os riscos mencionados e, portanto, não há demanda para elaboração dos mapas. No entanto, é essencial que os municípios monitorados quanto ao risco de desastres contenham com um mapeamento adequado como instrumento de planejamento. Atualmente, instituições como a Agência Nacional de águas (ANA), Serviço Geológico do Brasil (CPRM) e Instituto de Pesquisas Tecnológicas (IPT) têm atuado na elaboração e na atualização desses mapas. Alguns municípios também contrataram diretamente os serviços de mapeamento.

Para compreensão e uso dos mapas de risco, deve haver fortalecimento institucional (investimento de recursos e pessoas) e da população, especialmente, por meio do reforço da defesa civil e dos núcleos comunitários.

\section{Zoneamento ou uso e ocupação do solo}

Mais da metade dos municípios brasileiros (54\%) possui legislação sobre zoneamento ou uso e ocupação do solo. Destacamos positivamente as regiões Norte e Sul do país, principalmente o estado de Santa Catarina, onde a quase totalidade dos municípios possui legislação sobre zoneamento ou uso e ocupação do solo. Os municípios localizados nos estados de Alagoas, Pernambuco e Ceará precisam ser incentivados quanto à criação dessa lei. 
Contudo, poucos municípios $(15 \%$ e $7 \%$, respectivamente) apresentam a lei de uso e ocupação do solo que contemple a prevenção de enchentes ou inundações graduais, ou enxurradas ou inundações bruscas, e a lei de uso e ocupação do solo que contemple a prevenção de escorregamentos ou de deslizamentos de encostas. Por se tratar de legislações correlatas, os municípios que se dedicam à prevenção provavelmente terão as duas leis, exceto em casos em que haja riscos de apenas um processo isolado.

Cabe ressaltar que tanto o zoneamento quanto as leis de uso e de ocupação do solo complementam os planos diretores dos municípios ao estabelecerem critérios de uso e de ocupação em zonas específicas dos municípios. O município de Angra dos Reis (RJ), por exemplo, informou ter uma lei voltada à prevenção de inundações e não ter uma relativa à prevenção de deslizamento. No entanto, a sua lei de uso e de ocupação do solo, entre outras coisas, não permite edificações em terrenos em que as condições geológicas não são aconselháveis e em terrenos com declividades igual ou superior a 45ํㅜ (Angra dos Reis, 2009). Portanto, acredita-se que, mesmo que a prevenção de escorregamentos não esteja explícita no texto da lei, esta a contemplará.

\section{Leis específicas}

Os resultados sobre a existência de legislação específica (prevenção de inundações e de deslizamentos) mostram que a grande maioria dos municípios não possui legislações específicas para prevenção de desastres. Como os desastres, de maneira geral, são um tema de destaque recente no Brasil, é compreensível que as legislações ainda estejam em processo de elaboração, porém tal processo deve ser incentivado e estimulado.

É de fácil constatação que o número de municípios com as leis mencionadas anteriormente diminui à medida que as leis tornam-se mais específicas (Figura 2). É preciso oferecer suporte para a criação

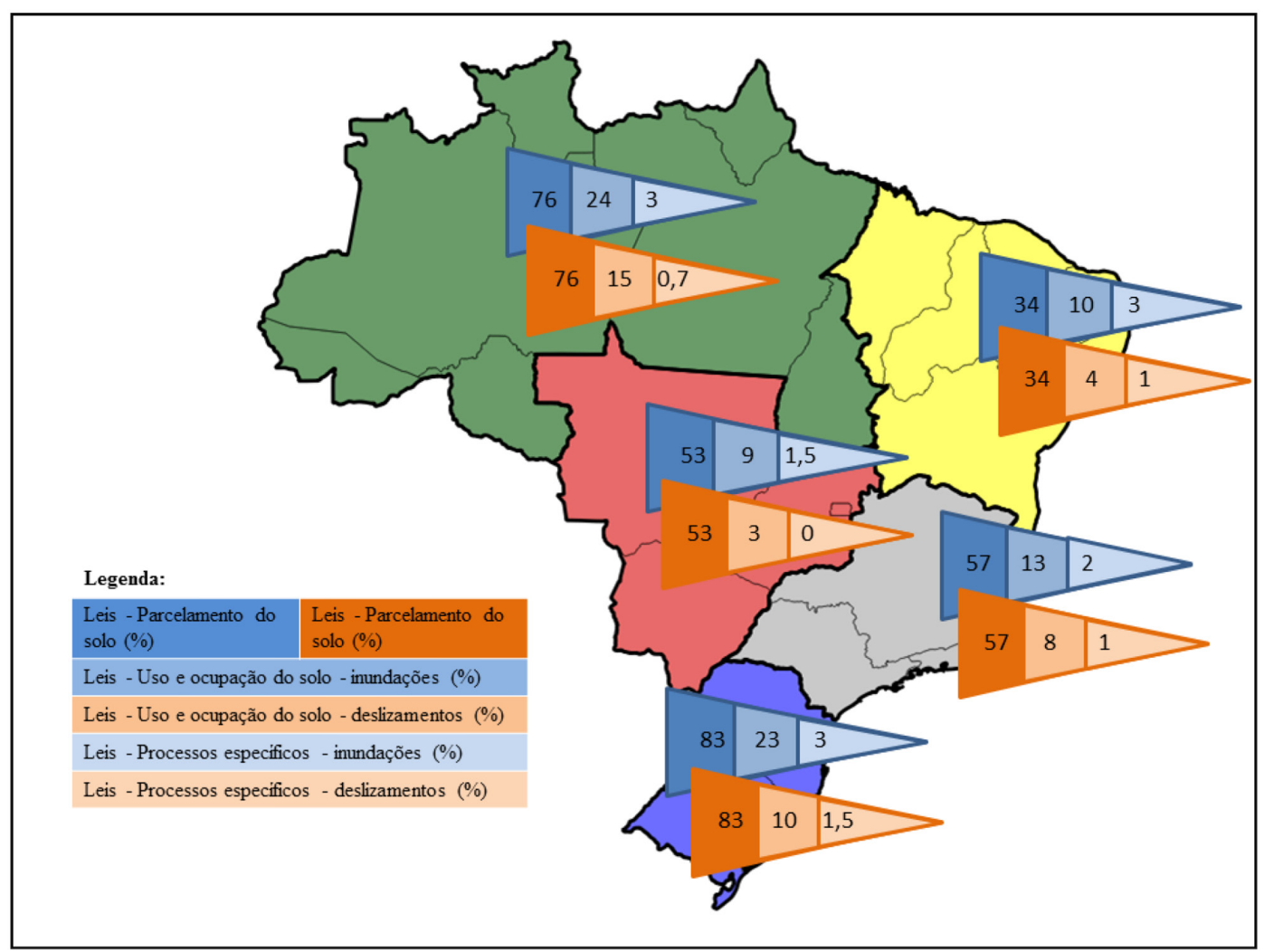

Figura 2 - Porcentagem de municípios que dispõem de leis espećificas para parcelamento do solo, uso e ocupação do solo, inundaç̦eses e deslizamentos, com valores separados por tipo de processo Fonte: IBGE (2014). 
dessas leis nos municípios em que forem necessárias e, principalmente, reforçar a fiscalização, bem como realizar campanhas educativas, com finalidade de impedir a ocupação de áreas impróprias. Em outras palavras, a legislação sem fiscalização e sem conscientização da população é um instrumento ineficaz.

De forma a inibir a perpetuação de áreas de risco, o administrador municipal deveria reconhecer o papel do zoneamento ou lei específica para induzir a ocupação adequada em áreas de expansão urbana. A PNPDEC, entre seus objetivos, estabelece:

$\mathrm{X}$ - estimular o ordenamento da ocupação do solo urbano e rural, tendo em vista sua conservação e a proteção da vegetação nativa, dos recursos hídricos e da vida humana;

XI - combater a ocupação de áreas ambientalmente vulneráveis e de risco e promover a realocação da população residente nessas áreas;

XII - estimular iniciativas que resultem na destinação de moradia em local seguro;

XIII - desenvolver consciência nacional acerca dos riscos de desastre (Brasil, 2012).

Nyakas (2009) enfatiza a necessidade da responsabilização dos danos ambientais, causados por ação antrópica nas ocorrências de defesa civil, objetivando a proteção ambiental e a prevenção de novos eventos.

Também devemos considerar que o planejamento do uso e de ocupação das terras em áreas urbanas e rurais e a gestão ambiental integrada devem ser prioridade em toda gestão municipal (Thomaziello, 2007).

\section{Articulação entre setores}

Tendo em vista o abrangente arcabouço normativo sobre a ocupação do solo e do uso de áreas consideradas de risco, bem como o número reduzido de municípios que têm conhecimento de tais instrumentos, torna-se necessário um trabalho amplo de divulgação e de explicação de tais leis e uma maior articulação entre os atores para definir a melhor forma de atuação institucional, pois a inibição da ocupação de áreas inadequadas e a criação de programas e políticas preventivas e de planejamento estão inter-relacionadas. Nota-se a preocupação da PNPDEC nesse aspecto, ao prever parágrafo único: A PNPDEC deve integrar-se às políticas de ordenamento territorial, desenvolvimento urbano, saúde, meio ambiente, mudanças climáticas, gestão de recursos hídricos, geologia, infraestrutura, educação, ciência e tecnologia e às demais políticas setoriais, tendo em vista a promoção do desenvolvimento sustentável (Brasil, 2012, art. 3ํㅜ).

Considerando os atuais desastres socioambientais e a discussão anterior, entende-se que os municípios demandarão auxílio estadual e federal para colocar em prática os instrumentos de ordenamento e de planejamento urbano, além de fortalecimento institucional para fiscalizar e gerir as áreas de risco. Há urgência na integração de instituições e dos atores locais para promover as ações e as diretrizes da PNPDEC. Para Freitas \& Cunha (2013), em decorrência do aumento progressivo da população urbana, o consequente aumento dos diferentes tipos de riscos urbanos (naturais, tecnológicos ou mistos) e a deterioração dos ecossistemas tornam imprescindível o traçado de ações integradas, envolvendo governo e parceiros locais, para definir políticas que transformem o conhecimento já consolidado em ações concretas em larga escala e que resultem em benefícios à sociedade.

A redução dos problemas socioambientais e a sugestão de medidas para adaptação às mudanças climáticas devem ultrapassar as políticas públicas municipais, embora a análise da vulnerabilidade estrutural das cidades caiba aos poderes locais (Kahn, 2014). Para Ribeiro (2008, p. 302):

[...] será preciso um esforço conjunto, que mobilize diversos ministérios, como o de Meio Ambiente, o de Cidades e o de Saúde, entre outros, já que muitas das novas cidades industriais ou mesmo as metrópoles regionais que incharam nos últimos anos não têm recursos técnicos e econômicos para financiar as alterações necessárias para se adaptarem às mudanças climáticas.

Todavia, os atores locais devem exercer os mecanismos de controle de uso e de ocupação do solo e seguir as diretrizes do ordenamento urbano com a proteção ambiental. Schäffer et al. (2011), analisando a área atingida por chuvas intensas na região Serrana do Rio 
de Janeiro, indicam que a preservação da vegetação nativa e a não ocupação das margens de cursos d'água, de áreas com declividade e topo de morro, entre outras protegidas, são a melhor maneira de evitar prejuízos com enchentes e com deslizamentos, inclusive a perda de vidas humanas.

Deve-se mudar a lógica de ações públicas desarticuladas e contrárias à legislação, conforme descreve DaMatta (1986): lei é um instrumento que faz a sociedade funcionar bem e é isso que precisamos enxergar.

\section{Considerações finais}

A inclusão da temática da Gestão de Riscos e Respostas a Desastres na Pesquisa de Informações Básicas Municipais do IBGE é um grande avanço e representa um marco dada a natureza sistemática da pesquisa, o que permitirá um acompanhamento das ações municipais em relação à gestão de riscos de desastres.

O acompanhamento contínuo da situação dos municípios é uma importante ferramenta para entender o grau de preparação dos municípios e para o planejamento e destinação de esforços por parte dos governos.

O conhecimento da importância do plano diretor para os municípios, bem como da lei sobre uso e ocupação do solo, vem sendo incorporado à estrutura de gestão dos municípios. Todavia, quando se analisam os instrumentos previstos na PNPDEC, como mapeamento de áreas de risco e carta geotécnica para subsidiar o planejamento municipal, verifica-se uma carência no uso de tais instrumentos, apontando que há pouco planejamento do espaço de risco nos municípios.

A maioria dos municípios não possui lei específica para prevenção de inundações ou de deslizamentos, mas, em alguns casos, tal previsão já foi incorporada em leis de uso e ocupação do solo, ou no zoneamento municipal, ou diretamente no plano diretor, a exemplo das cidades de Angra do Reis (RJ), Blumenau (SC) e São Paulo (SP). Observa-se que tais instrumentos são fundamentais para embasar atuação da fiscalização e evitar novas áreas de risco.

Para que a Lei n. 12.608/2012 possa ser aplicada de forma ampla e efetiva, é necessário que os inúmeros dispositivos previstos sejam regulamentados. Entre as ações mais urgentes, está a instituição do “[...] cadastro nacional de municípios com áreas suscetíveis à ocorrência de deslizamentos de grande impacto, inundações bruscas ou processos geológicos ou hidrológicos correlatos" (Brasil, 2012), pelo governo federal, já que várias outras medidas dependem desse ato.

Outras regulamentações importantes podem ser citadas, como a profissionalização e a qualificação, em caráter permanente, dos agentes públicos de proteção e defesa civil, necessárias ao funcionamento adequado das instituições municipais de defesa civil, pois permitiria que eles atuassem inclusive na atualização dos mapas de risco do município (ainda não previsto em lei), assim como analisar os mapeamentos existentes e os alertas recebidos de outras instituições.

\section{Referências}

Alheiros, M. M. (2006). Plano municipal de redução de risco. In C. S. Carvalho, \& T. Galvão (Orgs.), Prevenção de riscos de deslizamentos em encostas: guia para elaboração de políticas municipais (p. 58-75). Brasília: Ministério das Cidades, Cities Alliance. Recuperado em 11 de agosto de 2014, de http://www.cidades.gov.br/images/stories/ ArquivosSNPU/Biblioteca/PrevencaoErradicacao/Livro_ Curso_Capacitacao_Tecnicos_Municipais.pdf

Alves, C. D., Alves, H., Pereira, M. N. P., \& Monteiro, A. M. V. (2008). Análise dos processos de expansão urbana e das situações de vulnerabilidade socioambiental em escala intra-urbana. In Anais do IV Encontro Nacional da ANPPAS (p. 1-20). Brasília: ANPPAS.

Alves, H. P. F., \& Torres, H. G. (2006). Vulnerabilidade socioambiental na cidade de São Paulo: uma análise de famílias e domicílios em situação de pobreza e risco ambiental. São Paulo em Perspectiva, 20(1), 44-60.

Angra dos Reis. (2009, 23 de janeiro). Lei no 2092, de 23 de janeiro de 2009. Dispõe sobre o uso e ocupação do solo no município de Angra dos Reis. Angra dos Reis: Boletim Oficial do Município de Angra dos Reis. Recuperado em 29 de maio de 2015, de http://www.angra.rj.gov.br/ downloads/SMA/leis/lei_2092.pdf

Blumenau. Prefeitura Municipal. (2010, 23 de março). Lei complementar no 749, de 23 de março de 2010. Dispõe sobre o código de parcelamento do solo para fins urbanos no município de Blumenau e dá outras providências. Recuperado em 1 
de outubro de 2014, de http://www.leismunicipais.com. br/a/sc/b/blumenau/lei-complementar/2010/75/749/ lei-complementar-n-749-2010-dispoe-sobre-o-codigo-deparcelamento-do-solo-para-fins-urbanos-no-municipiode-blumenau-e-da-outras-providencias

Boff, L. (2010). Cuidar da Terra, proteger a vida: como evitar o fim do mundo. Rio de Janeiro: Record.

Brasil. (1979, 19 de dezembro). Lei no 6.766, de 19 de dezembro de 1979. Dispõe sobre o Parcelamento do Solo Urbano e dá outras Providências. Brasília: Diário Oficial da União.

Brasil. (1988). Constituição da República Federativa do Brasil de 1998. Brasília: Diário Oficial da União.

Brasil. (2001, 11 de julho). Lei no 10.257, de 10 de julho de 2001. Regulamenta os arts. 182 e 183 da Constituição Federal, estabelece diretrizes gerais da política urbana e dá outras providências. Brasília: Diário Oficial da União, seção 1, edição n 133.

Brasil. (2012, 11 de abril). Lei no 12.608, de 10 de abril de 2012. Institui a Política Nacional de Proteção e Defesa Civil - PNPDEC; dispõe sobre o Sistema Nacional de Proteção e Defesa Civil - SINPDEC e o Conselho Nacional de Proteção e Defesa Civil - CONPDEC; autoriza a criação de sistema de informações e monitoramento de desastres; altera as Leis $n^{\circ}$ s 12.340, de $1^{\circ}$ de dezembro de 2010, 10.257, de 10 de julho de 2001, 6.766, de 19 de dezembro de 1979, 8.239, de 4 de outubro de 1991, e 9.394, de 20 de dezembro de 1996; e dá outras providências. Brasília: Diário Oficial da União, seção 1, edição $n^{\circ} 70$.

Brasil. Ministério das Cidades. Instituto de Pesquisas Tecnológicas - IPT. (2007). Mapeamento de riscos em encostas e margens de rios. In C. S. Carvalho, E. S. Macedo, \& A. T. Ogura (Orgs.), Gerenciamento de áreas de risco: medidas estruturais e não-estruturais (p. 125-139). Brasília.

Bueno, L. M. M. (2011). Cidades e mudanças climáticas no Brasil: planejamento de medidas ou estado de risco? Sustentabilidade em Debate, 2(1), 81-98.

Carvalho, P. F., \& Braga, R. (2001). Perspectivas de gestão ambiental em cidades médias (p. 95-109). Rio Claro: LPM-UNESP.

Centro Nacional de Monitoramento e Alerta de Desastres Naturais - CEMADEN. (2014). Municípios monitorados: Cachoeira Paulista. Recuperado em 12 de março de 2014, de http://www.cemaden.gov.br/municipiosprio.php
Collischonn, E. (2009). Inundações em Venâncio Aires/RS: interações entre as dinâmicas natural e social na formação de riscos socioambientais urbanos (Tese de doutorado). Universidade Federal de Santa Catarina, Centro de Filosofia e Ciências Humanas, Florianópolis. Recuperado em 12 maio de 2015, de https://repositorio.ufsc.br/bitstream/ handle/123456789/92794/263811.pdf?sequence=1

Coutinho, M. P., Medeiros, J. D., Soriano, E., Londe, L. R., Leal, P. J. V., \& Saito, S. M. (2013). O Código Florestal Atual (Lei Federal oํ 12.651/2012) e suas implicações na prevenção de desastres naturais. Sustentabilidade em Debate, 4(2), 237-256.

Cutter, S. L. (1996). Vulnerability to environmental hazards. Progress in Human Geography, 20(4), 529-539. http:// dx.doi.org/10.1177/030913259602000407

DaMatta, R. (1986). O que faz o brasil, Brasil? Rio de Janeiro: Rocco.

Dorneles, A. C. B. (2010). 0 zoneamento e sua importância como um instrumento de planejamento urbano. Cadernos da Escola de Direito e Relações Internacionais, 13(1), 452467. Recuperado em 9 de setembro de 2014, de http:// apps.unibrasil.com.br/revista/index.php/direito/article/ viewFile/434/354

Ferreira, D., Albino, L., \& Freitas, M. J. C. C. (2011). Participação popular na prevenção e enfrentamento de desastres ambientais: resultado de um estudo piloto em Santa Catarina, Brasil. Revista Geográfica de América Central, 2(47E):1-17.

Freitas, M. I. C., \& Cunha, L. (2013). Cartografia da vulnerabilidade socioambiental: convergências e divergências a partir de algumas experiências em Portugal e no Brasil. urbe. Revista Brasileira de Gestão Urbana, 5(1), 15-31. http://dx.doi.org/10.7213/urbe.7783

Ganem, R. S. (2012). Gestão de desastres no Brasil (Estudo). Brasília: Câmara dos Deputados. Recuperado em 11 de fevereiro de 2015, de http://www2.camara. leg.br/documentos-e-pesquisa/publicacoes/estnottec/ tema14/2012_16213.pdf

Goerl, R. F. (2010). Estudo de inundações em Rio Negrinho - SC sob a ótica dos desastres naturais (Dissertação de mestrado). Universidade Federal de Santa Catarina, Centro de Filosofia e Ciências Humanas, Florianópolis.

Instituto Brasileiro de Geografia e Estatística - IBGE. (2014). Perfil dos municípios brasileiros 2013. Rio de Janeiro. 
Recuperado em 13 de outubro de 2014, de http://www. ibge.gov.br/home/estatistica/economia/perfilmunic/2013/ default.shtm

International Strategy for Disaster Risk Reduction - UNISDR. (2009). UNISDR terminology on disaster risk reduction. Geneva. Recuperado em 2 de julho, de 2014 de http://www. unisdr.org/eng/terminology/terminology-2009-eng.html

Kahn, S. (2014). Cidades com estrutura precária serão afetadas. Revista do Clima, Planeta Sustentável, 2. Recuperado em 24 de setembro de 2014, de http://www.planetasustentavel. abril.com.br/pdf/revista-do-clima_um-novo-tempo.pdf

Maffra, C. Q. T., \& Mazzola, M. (2007). As razões dos desastres em território brasileiro. In R. F. Santos (Org.), Vulnerabilidade ambiental: desastres naturais ou fenômenos induzidos? (p. 10-12). Brasília: Ministério do Meio Ambiente.

Marandola, E., Jr, \& Hogan, D. J. (2004). Vulnerabilidade: esboço para uma discussão conceitual. In Anais do seminário sobre questão ambiental urbana: experiências e perspectivas. Brasília: Núcleo de Estudos Urbanos e Regionais. CD-ROM.

Martine, G. (2007). O lugar do espaço na equação população/meio ambiente. Revista Brasileira de Estudos de População, 24(2), 181-190. http://dx.doi.org/10.1590/ S0102-30982007000200002

Martins, M. L. R. (2003). São Paulo: além do Plano Diretor. Estudos Av., 17(47), 167-186.

Medeiros, J. D. (2013). A demarcação de áreas de preservação permanente ao longo dos rios. Biotemas, 26(2), 261-270. http://dx.doi.org/10.5007/2175-7925.2013v26n2p261

Menezes, D. J. (2014). Zoneamento das áreas de risco de inundação na área urbana de Santa Cruz do Sul - RS (Dissertação de mestrado). Universidade Federal de Santa Maria, Santa Maria.

Netto, A. L. C., \& Avelar, A. S. (2007). 0 uso da terra e a dinâmica hidrológica. In R. F. Santos (Org.), Vulnerabilidade ambiental: desastres naturais ou fenômenos induzidos? (p. 59-73). Brasília: Ministério do Meio Ambiente.

Nyakas, W., Jr. (2009). Desastres humanos: necessidade de responsabilização dos danos ambientais pela polícia ambiental do estado de São Paulo (Monografia). Centro de Aperfeiçoamento e Estudos Superiores, Polícia Militar do Estado de São Paulo, São Paulo.

Oliveira, P. C., Fo, Andrade, A. R., Haberland, N. T., Pottker, G. S., \& Silvia, F. C. B. (2013). A importância das áreas verdes em uma cidade de pequeno porte: estudo de caso na cidade de Irati-PR. Revsbau, 8(1), 89-99.

Ribeiro, A. S., do Amaral, F. O. M., Silva, J. M., Jr, Costa, L. A., \& Oliveira, V. F. M. (2011). In A. S. Ribeiro (Coord.), Cidade Sustentável, bem-estar para todos: uso e ocupação do solo e seus impactos ambientais (p. 25). Palmas: Ministério Público do Estado do Tocantins. Recuperado em 08 de setembro de 2014, de https://athenas.mpto.mp.br//athenas/CMS/ download/2014/01/20/cartilha-cidade-sustentavel/

Ribeiro, W. C. (2008). Impactos das mudanças climáticas em cidades no Brasil. Parcerias Estratégicas, (27), $297-$ 322. Recuperado em 4 de setembro de 2014, de http:// www.cgee.org.br/atividades/redirect.php?idProduto=5321

Robaina, L. E. S. (2008). Espaço urbano: relação com os acidentes e desastres naturais no Brasil. Ciência e Natura, 30(2), 93-105.

Robaina, L. E. S., Kormann, T. C., Wiggers, M. M., \& Sccoti, A. A. V. (2010). Análise espaço-temporal das ocorrências de inundações e movimentos de massa no município de Caxias do Sul, RS. Ciência e Natura, 32(1), 159-172.

Santoro, P. F., Ferrara, L. N., \& Whately, M. (Orgs.). (2009). Mananciais: diagnóstico e políticas habitacionais. São Paulo: Instituto Socioambiental. Recuperado em 16 de setembro de 2014, de http://www.socioambiental.org/ banco_imagens/pdfs/10368.pdf

Santos, A. R. (2012). Enchentes e deslizamentos: causas e soluções. São Paulo: Pini.

São Paulo. (2014, 1 de agosto). Lei $n^{\circ}$ 16.050, de 31 de julho de 2014. São Paulo: Diário Oficial Cidade de São Paulo, ano 59, $\mathrm{n}^{\circ} 140$.

Schäffer, W. B., Rosa, M. R., de Aquino, L. C. S., \& Medeiros, J. D. (2011). Áreas de Preservação Permanente e Unidades de Conservação x Áreas de Risco: o que uma coisa tem a ver com a outra? (Biodiversidade, Vol. 41). Brasília: Ministério do Meio Ambiente. Recuperado em 8 de setembro de 2014, de http://www.mma.gov.br/estruturas/202/_arquivos/ livro_apps_e_ucs_x_areas_de_risco_202.pdf

TerraView. Recuperado em 15 de agosto de 2014, de http://www.dpi.inpe.br/terraview/index.php

Thomaziello, S. (2007). Usos da terra e sua influência sobre a qualidade ambiental. In R. F. Santos (Org.), Vulnerabilidade ambiental: desastres naturais ou fenômenos induzidos? (p. 23-38). Brasília: Ministério do Meio Ambiente. 
Tucci, C. E. M. (2008). Águas urbanas. Estudos Avançados, 22(63), 97-112. http://dx.doi.org/10.1590/ S0103-40142008000200007

Tucci, C. E. M. (2005). Gestão de inundações urbanas. Porto Alegre: Ministério das Cidades, Global Water Partnership, Wolrd Bank, Unesco.
Vedovello, R., \& Macedo, E. S. (2007). Deslizamento de encostas. In R. F. Santos (Org.), Vulnerabilidade ambiental: desastres naturais ou fenômenos induzidos? (p. 75-93). Brasília: Ministério do Meio Ambiente.

Recebido: Nov. 20, 2014

Aprovado: Maio 28, 2015 